\title{
School Dropout Intention and Self-esteem in Immigrant and Native Students Living in Poverty: The Protective Role of Peer Acceptance at School
}

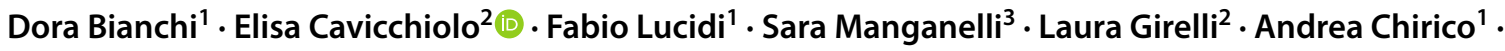 \\ Fabio Alivernini ${ }^{1}$
}

Accepted: 6 January 2021 / Published online: 24 January 2021

(c) The Author(s) 2021

\begin{abstract}
The psychological well-being at school of immigrant students living in poverty is currently an understudied topic in developmental psychology. This is an important shortcoming because this population, which is rapidly increasing in many western countries, is in a double minority condition and has a greater risk of experiencing psychological distress at school, in comparison with their native peers. In order to improve our understanding on this issue, the present two-wave study investigated the prospective relationships between peer acceptance and two aspects of well-being at school-intention to drop out of school and negative self-esteem - specifically focusing on the differential effect of having (vs. not having) an immigrant background. The participants were 249 preadolescents and adolescents living in poverty $\left(M_{\text {age }}=12.76 ; S D_{\text {age }}=2.34 ; 41.8 \%\right.$ girls; $19.3 \%$ immigrants) who were attending educational centres for disadvantaged minors. The poverty status of the participants was an inclusion criterion. A multilinear regression model with multigroup analysis was tested. As expected, the results showed that peer acceptance had a significant negative association with school dropout intentions and negative self-esteem only for immigrants, but not for natives. For immigrant students, the protective effect of peer acceptance was comparable to the stability over time of dropout intention and self-esteem, a result that has promising implications for prevention programs. The applied implications of the study for educational and clinical contexts are discussed.
\end{abstract}

Keywords School dropout intention $\cdot$ Negative self-esteem $\cdot$ Peer acceptance $\cdot$ Immigrants $\cdot$ Poverty

\section{Introduction}

Psychological well-being at school is a construct that has been broadly examined in literature (e.g. Zhou, Huebner, \& Tian, 2020). It is characterized by affective components, as well as behavioral indicators of positive adjustment (Renshaw \& Bolognino, 2017). Individual self-esteem-as an affective component—and school dropout—as a behavioral

Elisa Cavicchiolo

ecavicchiolo@unisa.it

1 Department of Developmental and Social Psychology, Sapienza University of Rome, Via dei Marsi 78, Rome, Italy

2 Department of Human, Philosophical and Educational Sciences, University of Salerno, Via Giovanni Paolo II, 132, Fisciano, Salerno, Italy

3 National Institute for the Evaluation of the Education System (INVALSI), Via Ippolito Nievo 35, Rome, Italy indicator - have been considered indicative aspects of psychological well-being at school (Bizumic, Reynolds, Turner, Bromhead, \& Subasic, 2009; Korhonen, Linnanmäki, \& Aunio, 2014; Ogle, Frazier, Nichols-Lopez, \& Cappella, 2016), although these two variables have rarely been investigated together in the context of school mental health (Wells, Miller, Tobacyk, \& Clanton, 2002).

The psychological well-being at school of immigrant students living in poverty is currently an understudied topic in developmental psychology. Nevertheless, this is a vulnerable population characterized by a double minority conditionbeing both immigrants and part of a disadvantaged social group — which makes them more exposed to peer discrimination and psychological distress at school during childhood and adolescence (Weeks \& Sullivan, 2019). As pointed out by Mc Andrew et al. (2015), a considerable number of immigrant families live below the poverty threshold, as a consequence of their migration history. For this reason, it is often difficult in research to distinguish the specific effects 
of immigrant background from those of persistent poverty in general (Archambault, Janosz, Dupéré, Brault, \& Andrew, 2017). In this regard, poverty itself is a condition frequently associated with higher rates of school dropout, poor selfesteem, and poor psychological well-being at school (Duncan \& Murnane, 2011; Sinclair et al., 2010).

Considering the steadily increasing number of immigrant students in European and Italian schools (Foundation for Initiatives and Studies on Multi-Ethnicity, ISMU, 2020; Ministry of Education, Universities and Research, MIUR, 2019), a better understanding of the school well-being of immigrant minors living in poverty is needed. Mass immigration to Italy is a relatively recent phenomenon, and there are still many difficulties in Italian schools in dealing with the special needs of foreign students (Milione, 2011). Immigrant children and adolescents in Italy are often subjected to social discrimination and peer victimization (Palladino, Nappa, Zambuto, \& Menesini, 2020), and the school system is not always able to successfully integrate their cultural and linguistic diversity (Milione, 2011). International studies suggest however that immigrant minors have certain specific risk and resilience factors. According to the segmented assimilation theory (Portes \& Rumbaut, 2001), the social context of reception can make a considerable difference, leading to either positive or negative developmental outcomes: in favorable social contexts immigrant adolescents may reach a positive adjustment at school despite a low socioeconomic status-even outperforming their native peers (Alivernini, Manganelli, \& Lucidi, 2018; Schwartz, Unger, Zamboanga, \& Szapocznik, 2010). Nevertheless, in the presence of adverse social conditions, they are often more vulnerable to negative outcomes (Klimidis, Stuart, Minas, \& Ata, 1994), and there is evidence that non-inclusive school contexts usually lead to problems in the adjustment of immigrant youths to school (Dimitrova, Chasiotis, \& Van de Vijver, 2016).

Recent findings on the developmental tasks of immigrant minors can help to explain these phenomena (SuárezOrozco, Motti-Stefanidi, Marks, \& Katsiaficas, 2018), suggesting that immigrant adolescents aim to attain a high level of social and cultural integration in the host community, and that school is the main social context of reception in which they can achieve this integration (Suárez-Orozco et al., 2018). As a consequence, immigrant students sometimes have higher levels of motivation and more positive attitudes toward school than natives (Liebkind, Jasinskaja-Lahti, \& Solheim, 2004; Vedder, Boekaerts, \& Seegers, 2005). However, when the school context is not inclusive and they find it difficult to be socially integrated, they could suffer from psychological distress (Dimitrova et al., 2016). Surprisingly, research on the psychological well-being at school for immigrant minors is still fairly limited.
According to the segmented assimilation theory (Portes \& Rumbaut, 2001), it is possible to expect perceived peer acceptance to play a key role in the psychological well-being of immigrant adolescents at school, and recent studies have provided initial evidence to support this idea (Motti-Stefanidi, Pavlopoulos, Mastrotheodoros, \& Asendorpf, 2020). Peer acceptance has a pivotal role in emotional and relational development in general (Harris, 1995): during preadolescence and adolescence, the perception of belonging to a peer group sustains the gradual processes of individuation and of increasing autonomy from the family (Rubin, Bukowski, \& Parker, 2006), protecting the individual's psychological well-being in spite of other contextual difficulties (Birkeland, Breivik, \& Wold, 2014). However, peer acceptance might play an additional role for immigrant adolescents, sustaining their processes of acculturation and of social integration, which take place mainly at school (Suárez-Orozco et al., 2018). As a consequence, the lack of peer acceptance might be specifically detrimental for the psychological wellbeing of immigrant students at school.

The present study investigated the role of peer acceptance at school in the development of school dropout intention and negative self-esteem-as indicators of psychological wellbeing at school—for immigrant preadolescents and adolescents living below the poverty threshold, compared with their native peers. The following sections will describe the relationships of peer acceptance with school dropout intention and self-esteem, as well as their specific connections with immigrant background.

\section{School Dropout Intention and Peer Acceptance}

The intention to drop out of school has strong associations with subsequent actual dropout in adolescence (Davis, Ajzen, Saunders, \& Williams, 2002), and, in this regard, it has been the object of many studies (e.g. Carsley, Heath, Gomez-Garibello, \& Mills, 2017; Eicher, Staerklé, \& Clémence, 2014). Conceptual models of dropout have consistently indicated that the combined effects of individual and contextual factors may lead preadolescents and adolescents to leave school early (review by Rumberger \& Lim, 2008). At the individual level, gender differences have consistently emerged in most studies, indicating that boys are more at risk of dropout from school (review by Ripamonti, 2018). Although school dropout increases with age, with a higher prevalence in late adolescence, it can be considered as the outcome of a long process that starts during the earliest years of school (Ripamonti, 2018). Recent studies have shown that dropout intention is present and measurable as early as elementary and junior high school (Lee, Chun, Kim, \& Lee, 2020; Oh, Jung, \& Lee, 2018). Low academic achievement is another frequent predictor of school dropout (Ripamonti, 2018). 
The socio-economic background is one of the main individual predictors of school dropout, with low family income and poverty conditions leading to more frequent dropout from all grades of school (Ripamonti, 2018; Rumberger \& Lim, 2008). Poverty predicts negative school outcomes through the mediating effect of poverty-related stressors, such as family conflicts, home removals, or daily hassles (Wadsworth et al., 2008). Stressors related to poverty and to immigrant background interact in various ways on school dropout (Archambault et al., 2017), suggesting the importance of more specific research targeting immigrant and native students living in poverty.

Regarding contextual risk factors for school dropout, studies have revealed the protective role of family supervision, support from teachers, and a positive school climate (see reviews by Ripamonti, 2018; Rumberger \& Lim, 2008). Conversely, the role of peers in school dropout intention has been less extensively explored, with most studies focusing on affiliation with deviant peers (Glaser, 2009), and on bullying and victimization (Cornell, Gregory, Huang, \& Fan, 2013) as predictors of early school leaving, due to negative peer influence. Only two studies have investigated the positive role of peers, indicating that participation in extracurricular activities with classmates is a protective factor that may act as a defense against school dropout during preadolescence and adolescence (Crispin, 2017; Mahoney, 2014), whereas the role of peer acceptance in preventing intention to drop out from school has been insufficiently studied. These sparse and generic findings suggest that the relation between peer acceptance and school dropout might be mediated by other factors, such as sharing learning activities with peers, leading to a greater interest in school.

However, the relationship between peer acceptance and dropout intention might be very different for immigrant students, with group-specific risk factors. Since school represents one of the main social contexts of reception for immigrant minors in the host country (Suárez-Orozco et al., 2018), peer acceptance at school may help them to feel well integrated in the host community. In accordance with the theoretical framework of the segmented assimilation theory (Portes \& Rumbaut, 2001), the research based on the peer nomination technique has confirmed that peer acceptance at school can be used to predict positive acculturation processes for immigrant adolescents (Motti-Stefanidi et al., 2020). This evidence, although it is still limited, indicates that it is worth further investigating the role of classmates in the psychological well-being of immigrant students. It seems plausible to suppose that not being accepted by their classmates might have more negative consequences for immigrants, such as the intention to drop out of school.

\section{Self-esteem and Peer Acceptance}

Self-esteem has been defined as a general evaluation of one's own worth and importance (Rosenberg, 1965), which develops gradually during childhood and adolescence and becomes more stable in early adulthood (Huang, 2010). Studies on the Rosenberg's model (1965) have suggested the existence of a positive and a negative component in selfesteem, working as two complementary dimensions (Huang $\&$ Dong, 2012). Positive self-esteem (satisfaction with the self) may be considered a good indicator of psychological well-being at school (Bizumic et al., 2009), as it averts depression and anxiety (Sowislo \& Orth, 2013), and it is positively associated with school engagement and academic achievement (Ogle et al., 2016). Conversely, negative selfesteem (dissatisfaction with the self) during adolescence is related to negative developmental outcomes, such as academic failure and dropout (Wells, Miller, Tobacyk, \& Clanton, 2002), mental disease, depression, and anxiety (Sowislo \& Orth, 2013), and it is very common among minors living in poverty (Veselska et al., 2010). Family income indeed has a well-proven impact on self-esteem, predicting negative self-concept in different domains for low income adolescents (Veselska et al., 2010). Sharp declines in individual selfesteem across adolescence are due to the perception of being part of a socially disadvantaged minority, such as being low income and/or immigrant in a more advantaged native community (Rhodes, Roffman, Reddy, \& Fredrik, 2004). This corpus of research has shown that native and immigrant adolescents living in poverty are highly vulnerable to developing negative self-esteem, suggesting the importance of studying group-specific protective factors.

Positive and negative self-esteem are strongly related to the quality of one's closest relationships with others and to perceived social approval (Leary, 2005). Accordingly, the "sociometer theory" (Leary, 2005) considers self-esteem as a subjective evaluation of one's effectiveness in social relationships, and thus as a meter of perceived social acceptance. Particularly during adolescence, the subjective perception of acceptance or inclusion within one's peer group has a significant role in building the positive component of self-esteem, and in sustaining the development of personal and social identity (Brown \& Larson, 2009). Several studies using subjective evaluations and/or sociometric measurement of peer acceptance have confirmed the positive association between peer acceptance and positive self-esteem in children and adolescents (Birkeland et al., 2014; Pinto, Veríssimo, Gatinho, Santos, \& Vaughn, 2015).

On the other hand, a meta-analysis (Blackhart, Nelson, Knowles, \& Baumeister, 2009) has disconfirmed the direct link between peer exclusion and the negative side of selfesteem, uncovering that individual self-esteem is sustained by positive acceptance, but it is not directly undermined 
by social exclusion. According to Leary (2005), individual self-esteem may result from a general evaluation of one's own eligibility for close social relationships and one's estimation of the probability of having such relationships in the future, rather than being a direct response to contextual events. Thus, the relationship between peer acceptance and negative self-esteem needs to be investigated in more depth.

In line with the segmented assimilation theory (Portes \& Rumbaut, 2001), the important role of the social context for immigrant students may establish a specific association between peer acceptance and negative self-esteem in immigrant adolescents, since this population has specific needs as regards peer relatedness. Immigrant adolescents are more subject to peer exclusion in the class group due to their cultural and ethnic diversity (Plenty \& Jonsson, 2017). Immigrants are not only overtly victimized, but also frequently exposed to subtle and hidden forms of exclusion by their native peers (Plenty \& Jonsson, 2017), as forms of social isolation and low acceptance. The literature suggests that the feeling of belonging to the school community is related to positive aspects of self-esteem and psychological well-being for immigrant adolescents, whereas feelings of isolation and exclusion are predictive of negative outcomes (Gummadam, Pittman, \& Ioffe, 2016). Overall, the research provides support for the hypothesis that peer acceptance at school may be a protective factor for immigrant students, contrasting negative self-esteem, and sustaining their well-being at school.

\section{The Current Study}

This two-wave study investigates the differential effect of immigrant background in the relationship between peer acceptance (measured at the baseline) and two components of psychological well-being at school: school dropout intention and negative self-esteem (measured seven months later). The study targeted a population of preadolescents and adolescents from the 6th to the 13th grade, who lived in conditions of poverty. Disentangling the specific effect of immigrant background from the general effects of poverty is made more difficult by the disruptive impact of poverty on school dropout (Duncan \& Murnane, 2011) and on self-esteem (Veselska et al., 2010). Therefore, in our study, the effect of poverty was controlled by the homogeneity of our participants, all of whom had a family income that was below the poverty threshold. Immigrant background has hitherto been insufficiently studied in the context of school dropout (Archambault et al., 2017), although previous research has suggested the important role of the social context in the adaptation and psychological well-being of immigrant minors (Schwartz et al. 2010).

Thus, we hypothesized that peer acceptance at school may protect immigrant students living in poverty from developing negative self-esteem and the intention to leave school early.
Gender, age, and school achievement were also controlled for, in conformity to previous studies (Bleidorn et al., 2016; Ripamonti, 2018). As suggested by the literature (Wells et al., 2002), we also expected to find a positive correlation between negative self-esteem and school dropout intention.

\section{Methods}

\section{Participants and Procedures}

The participants enrolled in this study were preadolescents and adolescents attending secondary school from the 6th to the 13th grade, and living in conditions of poverty. The participants were recruited from nine after-school educational centres for disadvantaged minors, in the urban and suburban areas of different Italian cities. These centers provide support services to minors in disadvantaged conditions, in the form of educational and recreational afternoon after-school activities. They are a reference point for several schools within their districts, while being independent from the schools themselves, and hosted students from many different classrooms and schools.

As a necessary inclusion criterion, the participants in the present study were all certified as being below the poverty threshold, according to the Italian official index of household welfare (Equivalent Economic Situation Indicator; ISEE). Written informed consent was obtained from the respondents and their parents. The data were collected via an online survey administered in the educational centres under the supervision of trained researchers, so as to ensure the participants' privacy and the standardization of the research procedures. The study and its procedures were in conformity with the Italian national ethical guidelines.

At the baseline level of data collection (time 1, April/ May), all the minors from the 6th to the 13th grade attending the nine educational centres in that period $(n=306)$, were invited to take part in the study. Only 5 minors refused, and the online questionnaire was therefore administered to 301 preadolescents and adolescents. At the moment of the second data collection, seven months later (time 2, October/ November), 52 of the original participants could not be contacted, as they were no longer attending the after-school centres for various reasons (e.g. their families had moved, or they had reached the age of 19 and were no longer eligible to attend the centres), and they were therefore excluded from the study. Overall, we obtained a response rate of $98.4 \%$ at the baseline, and of $81.4 \%$ at time 2 . The high response rate at the baseline probably reflected the trustful and positive climate of educational centers and was in line with recent studies on Italian adolescents (Bianchi, Lonigro, Baiocco, Baumgartner, \& Laghi, 2020). The attrition between waves is in line with the response rates in other longitudinal studies 
on adolescent samples (Van der Vorst, Engels, Meeus, \& Deković, 2006). A set of one-way ANOVAs was conducted on the baseline data, entering participation groups (only first wave, vs. both waves) as between-subject variable, in order to test if the included and excluded participants were significantly different on the study variables. These analyses did not detect any difference in the study variables between the participants who were excluded, and those who were included.

Thus, the final sample consisted of 249 preadolescents and adolescents living in poverty, and attending school from the 6th to the 13th grades $\left(M_{\text {age }}=12.76 ; S D_{\text {age }}=2.34\right.$, age range: $9-18 ; 104$ girls and 145 boys). Forty-eight of the participants (19.3\%) had an immigrant background, with 25 first generation immigrants and 23 second generation immigrants. This percentage is in line with the overall figures for low-income immigrant students attending Italian schools according to the most recent national reports (ISMU, 2020; MIUR, 2019), suggesting that our participants can be considered a good representation of the population of immigrant students living below the poverty threshold in Italy. Ethnic origin and languages spoken in the family were not investigated in the present study so as to protect the privacy of the minors, but according to national data most immigrant students in Italian schools come from other European countries or North Africa, with Romanian, Albanian and Moroccan students alone accounting for around $45 \%$ of all foreign students in lower secondary school, and $40 \%$ of those in upper secondary school (MIUR, 2019).

The first generation immigrants in our sample were all enrolled in the current school year and, at the time of baseline data collection, they had spent a minimum period of 8 months in the Italian school system. Due to the duration of school attendance, all the immigrant minors were able to understand the research questionnaires, which were administered in the Italian language.

\section{Measures}

\section{Socio-demographic Information}

The gender, age, and country of birth (Italy vs. abroad) of the participants were collected, as well as the country of birth of their parents. Participants who were born in a foreign country (first generation immigrants), or participants who were born in the host country to foreign-born parents (second generation immigrants) were considered as having an immigrant background, according to the criteria adopted by the Organization for Economic Co-Operation and Development (2014). Gender ( $0=$ girls; $1=$ boys $)$ and immigrant background $(0=$ native; $1=$ immigrant $)$ were dummy-coded.

\section{School Achievement}

In line with previous studies (e.g. Niepel, Brunner, \& Preckel, 2014), academic achievement was measured on the basis of self-reported school grades. For each participant, a mean score of achievement was computed by calculating the average of self-reported grades for mathematics and Italian language during the previous school term. Grades in these subjects, which are considered to be the two main subjects in Italy, are closely correlated with students' final academic achievement ( $r>0.80$; Martini, 2016). They therefore represent an effective measure of school achievement.

The study of Italian language includes several skills such as listening, oral production and interaction, reading and comprehension, writing, vocabulary, grammar, and includes the study of Italian literature. In the Italian school system, marks of $\geq 6$ indicate a satisfactory level. In our study, these grades ranged from 4 to 10 . Since the educational centres were not directly in contact with the participants' schools, only self-report grades, rather than officially registered grades, were available for our study. However, self-reported school grades are closely correlated with official school grades, and they reliably predict future educational outcomes (Dickhäuser \& Plenter, 2005).

\section{School Dropout Intention}

Intention to drop out of school was measured by three items retrieved from previous studies (Hardre \& Reeve, 2003; Italian adaptation by Alivernini \& Lucidi, 2011): "I sometimes consider dropping out of school" (item 1); "I intend to drop out of school" (item 2); "I sometimes feel unsure about continuing my studies year after year" (item 3 ). Each item was rated on a 5-point Likert scale ranging from 1 (never) to 5 (very often). The scale proved to have good reliability, criterion validity, and consistency across time in previous research (Alivernini \& Lucidi, 2011; Hardre \& Reeve, 2003), and it also reached excellent reliability in our sample (Cronbach's alpha of 0.92 at T1, and 0.87 at T2), according to benchmarks proposed by Ponterotto and Ruckdeschel (2007). Similar measures of school dropout intention have been successfully used in recent studies on minors attending primary, lower and upper secondary school (Lee et al., 2020; Oh et al., 2018), providing evidence about the feasibility of measuring school dropout intention in all school grades.

\section{Negative Self-esteem}

As suggested by previous studies (Birkeland et al., 2014), the self-esteem was evaluated by four items taken from the adolescent version of the Global Negative Self-Evaluation Scale (Alsaker \& Olweus, 1986), an instrument adapted from the negative self-esteem dimension of the Rosenberg 
Self-Esteem Scale (Rosenberg, 1965; Italian validation by Prezza, Trombaccia, \& Armento, 1997). The items were rated on a 5-point Likert scale from 1 (never) to 5 (very often), with higher scores indicating a greater degree of negative self-evaluation (a sample item was: "I certainly feel useless at times"). The instrument has been shown to have good psychometric properties in preadolescent and adolescent samples, demonstrating good reliability, external validity, and measurement invariance across time as well as across gender, in previous studies (Birkeland et al., 2014; Alsaker \& Olweus, 1986). The scale also achieved an excellent level of reliability in our study (Cronbach's alpha of 0.86 at $\mathrm{T} 1$, and 0.86 at $\mathrm{T} 2$ ).

\section{Peer Acceptance}

The level of peer acceptance perceived at school was evaluated by the 4-item Acceptance subscale from the Classmate Social Isolation Questionnaire for adolescents (CSIQ-A; Cavicchiolo, Girelli, Lucidi, Manganelli, \& Alivernini, 2019). The CSIQ-A is a self-report questionnaire validated on Italian adolescents and consisting of two dimensions: Acceptance-which measures overall acceptance within the class group-and Friendship-which assesses friendship with classmates also outside the school context. For the purposes of the present study, only the first dimension was used. The Acceptance items measured the number of classmates with whom the participants have good relationships at school, on the basis of some self-reported behavioral indicators (e.g. "How many of your classmates speak with you?"; "How many of your classmates do you talk with or exchange messages with on your mobile phone?"). Items were rated on a 5 -point Likert scale $(1=$ none; $2=$ very few; $3=$ some; $4=$ many; $5=$ all), with higher scores indicating a greater degree of peer acceptance. Classroom size in Italian schools may range from a minimum of 18 to a maximum of 28 students per class (Presidential Decree number 81 of March 20, 2009), and according to the most recent studies on national representative samples, the average number of students per class is around 21 (e.g. Alivernini, Cavicchiolo, Manganelli, Chirico, \& Lucidi, 2020). In the Italian school system, the students attend all lessons with the same classmates for a succession of school years, with changes in the compositions of classes occurring only in the transition from primary to lower secondary school, and from lower to upper secondary school. The CSIQ-A has been shown to have good psychometric properties in preadolescents and adolescents, demonstrating good criterion validity, internal consistency, and measurement invariance across different genders and immigrant backgrounds (Alivernini \& Manganelli, 2016; Cavicchiolo et al., 2019). Reliability also was good in the current study (Cronbach's alpha of 0.79 at T1).

\section{Data Analysis}

Statistical analyses were performed by using version 8.0 of the statistical modelling software programme MPLUS (Muthén \& Muthén, 2017). In order to test our hypotheses on the differential effects of immigrant background on the relationships between peer acceptance, school dropout intention and negative self-esteem, we tested a multivariate regression model with a multi-group analysis, using the Maximum Likelihood estimator. The baseline level of peer acceptance was defined as a statistical predictor of both school dropout intention and negative self-esteem at T2, while controlling for their corresponding baseline levels. Gender, age, and school achievement measured at $\mathrm{T} 1$ were also controlled as covariates. The T2 levels of school dropout intention and negative self-esteem were set to correlate. Immigrant background was used as grouping variable, and a series of multi-group analyses were performed to test the model in the two groups of natives and immigrants. Following a procedure acknowledged in previous studies (Matthews, 2017) the first multigroup model was run allowing the parameters to vary freely between groups, while in the second multigroup model all parameters were constrained to be equal across groups. The two models were compared with a $\chi^{2}$ difference test to determine if the unconstrained model explained the data significantly better than the more conservative constrained model. Then, independent Wald $\chi^{2}$ tests were performed to determine which specific paths significantly differed between groups. An adjusted model was tested in which only the significant paths emerged by the Wald $\chi^{2}$ tests were allowed to vary freely between groups, and the adjusted model was finally compared with the more conservative constrained model.

The variables were entered into the model as observed variables in order to conserve statistical power due to the modest sample size. Goodness of fit of the models was assessed with the chi-square test statistic and the following fit indices: the Comparative Fit Index (CFI) and the Tucker-Lewis index (TLI), both of which should be higher than 0.95 in a good model fit (Hu \& Bentler, 1999); as well as the Root Mean Square Error of Approximation (RMSEA) and the Standardized Root Mean Square Residual (SRMR), which should both be lower than 0.05 in an acceptable fit (Kaplan, 2000).

\section{Results}

The assumptions of normality were verified on the variables entered into the model, ensuring that skew and kurtosis values were within accepted ranges $( \pm 2$; Tabachnick \& Fidell, 2013; see Table 1). Descriptive statistics and differences 
Table 1 Descriptive statistics on the study variables

\begin{tabular}{|c|c|c|c|c|c|c|c|c|c|c|}
\hline & \multirow[t]{2}{*}{ Range } & \multirow[t]{2}{*}{ Skewness } & \multirow[t]{2}{*}{ Kurtosis } & \multicolumn{2}{|c|}{ Natives } & \multicolumn{2}{|c|}{ Immigrants } & \multirow[t]{2}{*}{$F(d f)$} & \multicolumn{2}{|c|}{ Total sample } \\
\hline & & & & $M$ & SD & $M$ & $\mathrm{SD}$ & & $M$ & $\mathrm{SD}$ \\
\hline School achievement T1 & $4-10$ & 0.28 & -0.19 & 6.86 & 1.18 & 6.82 & 1.22 & $F(1,248)=0.03$ & 6.85 & 1.19 \\
\hline Peer acceptance T1 & $1-5$ & -0.58 & 0.11 & 3.69 & 0.86 & 3.73 & 0.83 & $F(1,248)=0.09$ & 3.70 & 0.85 \\
\hline School dropout intention $\mathrm{T} 1$ & $1-5$ & 0.95 & -0.09 & 2.26 & 1.26 & 1.64 & 0.92 & $F(1,248)=10.23^{*}$ & 2.14 & 1.22 \\
\hline School dropout intention $\mathrm{T} 2$ & $1-5$ & 0.78 & 0.25 & 2.25 & 1.07 & 2.07 & 1.18 & $F(1,248)=1.13$ & 2.22 & 1.09 \\
\hline Negative self-esteem T1 & $1-5$ & 1.16 & 0.94 & 1.98 & 0.97 & 2.17 & 1.11 & $F(1,248)=1.35$ & 2.02 & 0.99 \\
\hline Negative self-esteem T2 & $1-5$ & 1.30 & 1.39 & 1.91 & 0.94 & 2.10 & 1.07 & $F(1,248)=1.42$ & 1.95 & 0.96 \\
\hline
\end{tabular}

$* p<0.01$

Table 2 Bivariate correlations between study variables

\begin{tabular}{|c|c|c|c|c|c|c|c|c|c|}
\hline & 1 & 2 & 3 & 4 & 5 & 6 & 7 & 8 & 9 \\
\hline 1. Gender $(0=$ girls; $1=$ boys $)$ & 1 & & & & & & & & \\
\hline 2. Age & 0.001 & 1 & & & & & & & \\
\hline $\begin{array}{l}\text { 3. Immigrant background } \\
(0=\text { natives; } 1=\text { immigrants })\end{array}$ & -0.04 & $.14^{*}$ & 1 & & & & & & \\
\hline 4. School achievement T1 & -0.12 & $-0.41 * * *$ & -0.01 & 1 & & & & & \\
\hline 5. Peer acceptance T1 & 0.09 & 0.01 & 0.02 & 0.08 & 1 & & & & \\
\hline 6. School dropout intention T1 & $0.17 * *$ & 0.10 & $-0.20^{* *}$ & $-0.15^{* *}$ & -0.04 & 1 & & & \\
\hline 7. School dropout intention $\mathrm{T} 2$ & $0.20 * *$ & -0.02 & -0.07 & -0.01 & 0.02 & $0.45^{* * *}$ & 1 & & \\
\hline 8. Negative self-esteem T1 & -0.10 & 0.09 & 0.07 & -0.09 & $-0.34 * * *$ & $0.13^{*}$ & 0.05 & 1 & \\
\hline 9. Negative self-esteem T2 & -0.10 & 0.09 & 0.08 & -0.04 & $-0.25 * * *$ & 0.06 & $0.16^{* *}$ & $0.48 * * *$ & 1 \\
\hline
\end{tabular}

$* p<0.05 ; * * p<0.01 ; * * * p<0.001$

between natives and immigrants are shown in Table 1. Correlations between study variables are shown in Table 2 .

The unconstrained multi-group model showed a good fit to the data: $\chi^{2}(4)=2.06, p=0.72$; RMSEA $=0.000$; $\mathrm{CFI}=1.00 ; \mathrm{TLI}=1.09 ; \mathrm{SRMR}=0.01$. The totally constrained multi-group model did not fit the data very well: $\chi^{2}(15)=25.51, p=0.04 ;$ RMSEA $=0.07 ; \mathrm{CFI}=0.93$; $\mathrm{TLI}=0.87$; SRMR $=0.08$. The Chi-square difference test conducted on the two models indicated that constraining the model's parameters significantly worsened the fit indexes: $\Delta \chi^{2}(11)=23.45, p=0.01$. Subsequently, a series of Wald $\chi^{2}$ tests were conducted on individual paths. Both the path from peer acceptance to school dropout intention, Wald $\chi^{2}$ $(1)=6.49, p=0.01$, and the path from peer acceptance to negative self-esteem, Wald $\chi^{2}(1)=6.90, p=0.008$, showed significant differences between natives and immigrants. The adjusted model, in which only the two above-mentioned parameters were allowed to vary freely between the groups, showed a good fit: $\chi^{2}(13)=13.99, p=0.37$; $\operatorname{RMSEA}=0.02$; $\mathrm{CFI}=0.99 ; \mathrm{TLI}=0.99 ; \mathrm{SRMR}=0.04$, and described the data significantly better than the totally constrained model: $\Delta \chi^{2}(2)=11.52, p=0.003$.

The final adjusted model accounted for $26.4 \%$ of variance for school dropout intention $(p<0.001)$ and $19.2 \%$ of variance for negative self-esteem $(p<0.001)$ in the native group, while in the immigrant group the explained variance was $19.4 \%$ for school dropout intention $(p=0.01)$, and $50.2 \%$ for negative self-esteem $(p<0.001)$. The results indicated that peer acceptance was significantly and negatively related to school dropout intention in the immigrant group $(\beta=-0.29, \mathrm{SE}=0.12, p=0.02)$, but not in the native group $(\beta=0.09, \mathrm{SE}=0.06, p=0.11)$, and that it was significantly and negatively related to negative self-esteem for immigrants $(\beta=-0.36, \mathrm{SE}=0.10, p<0.001)$ but not for natives $(\beta=-0.05, \mathrm{SE}=0.07, p=0.43)$. In both groups, school dropout intention was positively associated with gender and baseline levels of school dropout intention, whilst negative self-esteem was positively associated with its baseline level. Finally, school dropout intention and negative self-esteem were positively correlated in both groups. The results of the adjusted model are presented in Fig. 1. Two simple slope analyses (Aiken \& West, 1991) were also run for school dropout intention and for negative self-esteem, by plotting the predicted values of the dependent variables as a function of peer acceptance, at the two levels of immigrant background (natives $=0$; immigrants $=1$ ), controlling for the effects of the covariates. The simple slopes are shown in 


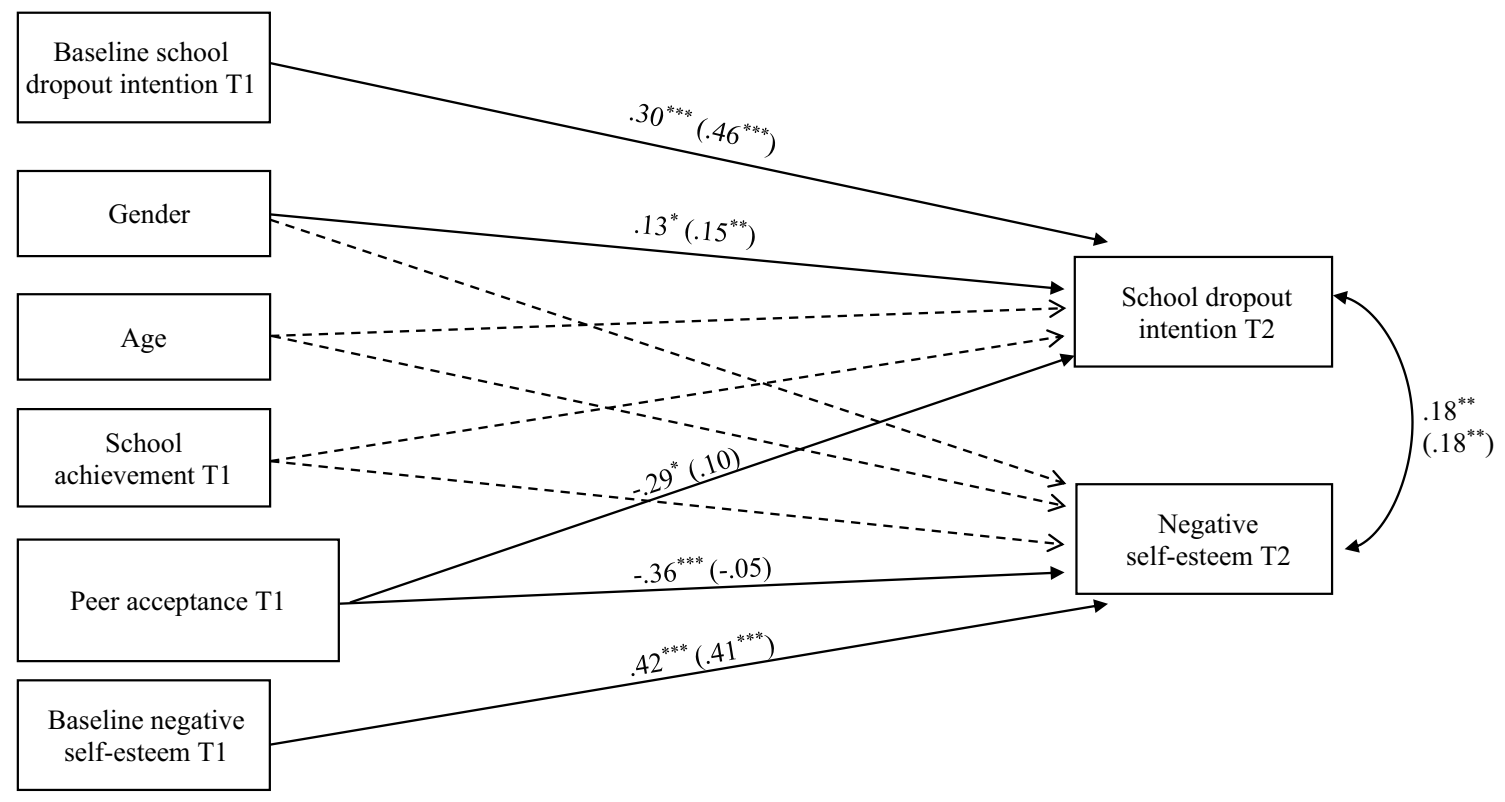

Fig. 1 Multigroup adjusted model for immigrants and natives. Notes: Parameter estimates are standardized. Estimates for natives are reported in brackets, estimates for immigrants are outside brackets. Dashed lines represent non-significant relationships. ${ }^{*} p<.05 ; * * p<.01 ; * * * p<.001$

Fig. 2 Moderating effect of immigrant background in the relationship between peer acceptance at $\mathrm{T} 1$ and school dropout intention at $\mathrm{T} 2$, controlling for gender, age, school achievement and $\mathrm{T} 1$ baseline level of school dropout intention

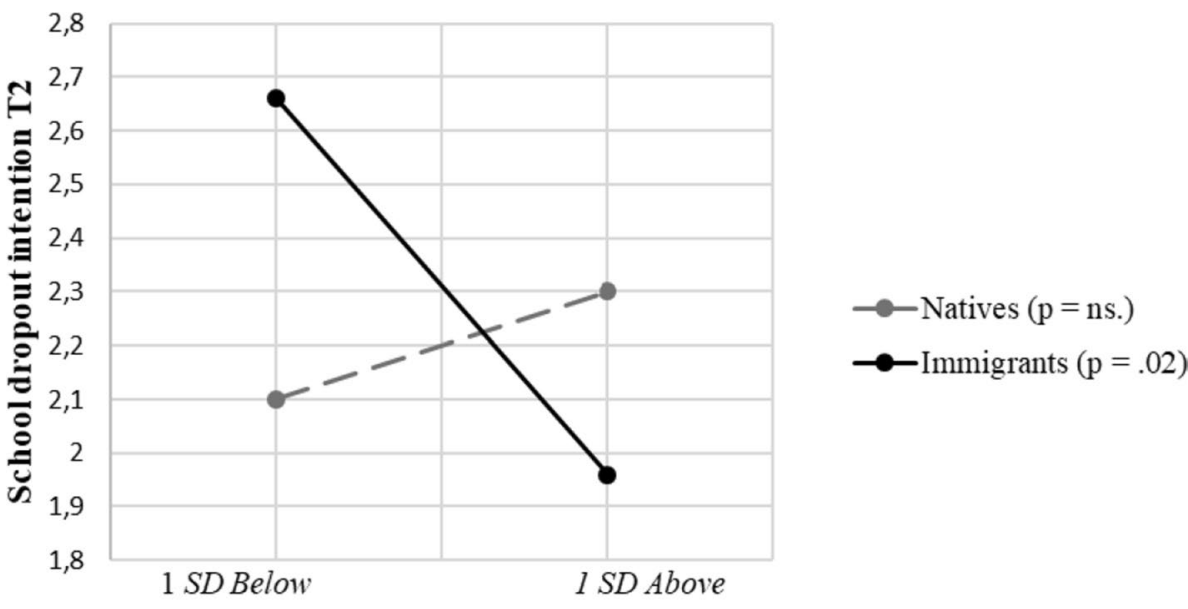

Peer Acceptance T1
Fig. 2 for school dropout intention, and in Fig. 3 for negative self-esteem.

\section{Discussion}

This study, conducted on a population of students living below the poverty threshold, explored the differential role of immigrant background in the associations of peer acceptance with changes in school dropout intention and negative self-esteem over time, controlling for gender, age, and school achievement. According to the segmented assimilation theory (Portes \& Rumbaut, 2001; Schwartz et al., 2010), the characteristics of the social context can shape the adaptation processes of immigrant minors, leading to adjusted or maladjusted outcomes. Consistently with this theoretical model, and supporting previous knowledge about the role of peers for the well-being of immigrant adolescents (MottiStefanidi et al., 2020), the findings of our study indicated that peer acceptance at school is a protective factor associated with the reduction of school dropout intention and of negative self-esteem among immigrants living in poverty, whereas the same relationships were not confirmed among their native peers.

To the best of our knowledge, this is the first study to detect the specific role of having (vs. not having) an 
Fig. 3 Moderating effect of immigrant background in the relationship between peer acceptance at $\mathrm{T} 1$ and negative self-esteem at $\mathrm{T} 2$, controlling for gender, age, school achievement, and T1 baseline level of negative self-esteem

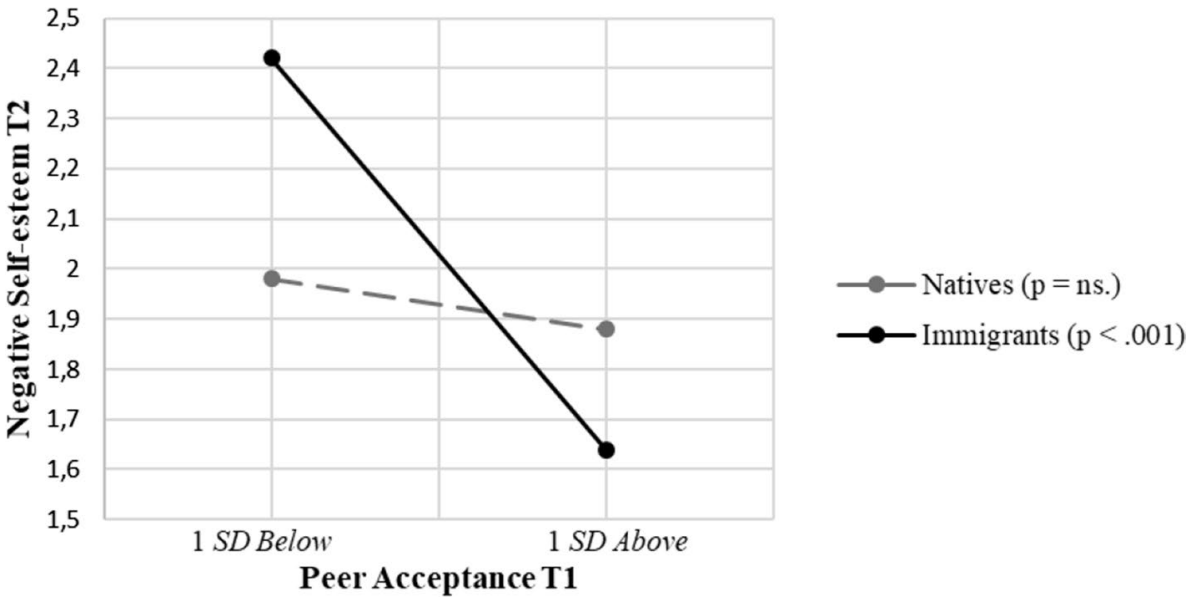

immigrant background on the association of acceptance by classmates with school dropout intention and negative selfesteem, disentangling the effects of being an immigrant from those of living below the poverty threshold. The need for relatedness may be particularly salient to immigrants living in poverty, as they are more subject to social discrimination due to their double minority status (Alivernini, Manganelli, Cavicchiolo, \& Lucidi, 2019; Plenty \& Jonsson, 2017). Our findings have confirmed and expanded those of previous studies, showing that immigrant minors living in poverty who perceive themselves as not being accepted by their classmates may be more likely to develop the intention to leave school, and may suffer an increase in negative self-esteem over time. These results did not apply to native adolescents in conditions of poverty, indicating that native students are probably not as sensitive to peer acceptance/ rejection as their immigrant peers. Various other contextual and individual variables may moderate the link between perceived peer acceptance and well-being at school in the native low-income population, as suggested by the absence of clear findings in previous research (Blackhart et al., 2009; Ripamonti, 2018).

In our study, we controlled for individual differences related to gender, age, and school achievement, in consideration of the existing literature (Bleidorn et al., 2016; Ripamonti, 2018), but only gender proved to have a significant role on changes in school dropout intention over time in both groups. This result confirmed the fact that boys are more likely to leave school earlier (Eicher et al., 2014), and suggested that gender is a risk factor in both natives and immigrants. The fact that no other individual differences emerged in either of the groups may be due to the high degree of homogeneity of our sample, since the overall negative impact of poverty on school dropout (Duncan \& Murnane, 2011) and self-esteem (Veselska et al., 2010) may annul the variations expected in the general population.
In accordance with previous studies (Wells et al., 2002), our results also showed that the school dropout intention was positively related to negative self-esteem. Confirming past research (Eicher et al., 2014; Orth, Robins, Widaman, \& Conger, 2014), in our study, these two variables were quite stable over time, as shown by the significant positive effects of their baseline levels. More interestingly, in the immigrant group the relationships of peer acceptance with school dropout intention and negative self-esteem were inverse and almost equal in magnitude to those of the long-term stability of the latter two variables.

Findings from this study are a promising indication of the positive role of peer acceptance for the well-being at school of immigrants living in poverty, even if the results are necessarily limited to the characteristics of our sample. Several studies have found that dropout intention is relatively stable across school years (Alivernini \& Lucidi, 2011; Eicher et al., 2014), however, the protective factors that emerged in prior research have rarely showed effects comparable to the persistence of this intention. Similarly, our findings suggest the potential of peer acceptance to oppose the persistence of negative self-esteem over time, indicating new directions for prevention programs targeted at immigrant students. This important role of peer acceptance for immigrant students living in poverty suggests that prevention and intervention programs may be more likely to succeed if they focus on strengthening the classroom group.

One of the limitations of this study is the modest sample size, which was due to the difficulties in identifying and contacting such a specific population, and it has some implications, above all the fact that some relationships with small effect sizes may not have been detected. Nevertheless, several significant relations have been discovered, which can make an important contribution to this field of research. The percentage of immigrant participants (19\%) was consistent with the percentage of low-income immigrant students that attend Italian schools (ISMU, 2020; MIUR, 
2019). However, it will be worth conducting future studies on larger samples, in order to explore the possible existence of other important effects, which may be specific for immigrants or for natives. A second limitation is the absence of information about the ethnic origins and the family language of the immigrant participants, as well as their ages at the time of their arrival in Italy. These characteristics were not investigated in the present study, in order to safeguard the privacy of the minors involved, although it is acknowledged that most of the immigrant minors in Italian schools are from other European countries and from North Africa (MIUR, 2019). Future research should also control for these variables, in order to account for the expectable heterogeneity in the immigrant group. A third limitation was the adoption of a two-wave research design, and it will be necessary to apply some more complex longitudinal models in order to verify this pattern of results.

Finally, our findings will hopefully be confirmed by future research that also controls for the problem behaviors and clinical conditions that might be involved in the psychological well-being at school of immigrant and native students living in poverty. For example, immigrants living in poverty may well be more exposed to internalizing symptoms (such as anxiety and depression), due to the migration history of their families, or to the discrimination by peers that they suffer. On the other hand, natives living in poverty might have more behavioral problems, due to the difficulties in their families. These variables could probably help to explain the relationships that have emerged in our study, as mediating or moderating factors, and could point the way for future developments in this area of research.

\section{Conclusion}

This study is the first evidence for the differential role of immigrant background in the relations of peer acceptance with subsequent school dropout intention as well as negative self-esteem. Peer acceptance at school is negatively associated with school dropout-intention and negative selfesteem in immigrant students living in poverty, but not in their native peers. This study has revealed the specific role of immigrant background, controlling for the overall impact of low socioeconomic status, providing unique evidence for the different developmental needs of immigrant (vs. native) students living in poverty.

The present study has research and practical implications. Our findings revealed the positive role of peer acceptance exclusively measuring the number of social interactions, but not their quality. Therefore, future research should be directed to further explore which different aspects of peer relationships may contribute to school engagement and self-esteem in immigrant vs. native students. School psychologists working with at-risk students will be able to take into account the specific needs of immigrants living in poverty, by dedicating special attention toward supporting their relations with their peers. Our findings indicate that prevention programs for school dropout should focus more on the classroom group, encouraging and sustaining the development of positive peer relationships, combating prejudice, and attempting to prevent discrimination and social exclusion among classmates. Clinical support for adolescents who are thinking of dropping out of school should take into account possible vulnerability factors related to gender, low family income, and immigrant background, while also considering the role of negative self-esteem as an important correlate of dropout intention and an indicator of psychological well-being at school.

Author Contributions DB conceived of the study, performed the statistical analyses, participated in interpretation of the data, and drafted the manuscript; EC performed the statistical analyses, participated in interpretation of the data and helped to draft the manuscript; SM, LG, and AC participated in data collection and interpretation, helped to draft the manuscript and critically revised the drafted manuscript for important theoretical contents; FL critically revised the drafted manuscript for important theoretical contents; FA conceived of the study, supervised the study design and all the statistical analyses, and critically revised the drafted manuscript for important theoretical contents. All authors read and approved the final manuscript.

Funding Open Access funding provided by Università degli Studi di Salerno. This research did not receive any funding.

\section{Compliance with Ethical Standards}

Ethical Approval All procedures performed in studies involving human participants were in accordance with the ethical standards of the institutional research committee of Ricerca Azione Onlus and with the 1964 Declaration of HELSINKI and its later amendments or comparable ethical standards.

Informed Consent Informed consent was obtained from all the individual participants included in the study.

Conflict of interest The authors declare that they have no conflicting or competing interests.

Open Access This article is licensed under a Creative Commons Attribution 4.0 International License, which permits use, sharing, adaptation, distribution and reproduction in any medium or format, as long as you give appropriate credit to the original author(s) and the source, provide a link to the Creative Commons licence, and indicate if changes were made. The images or other third party material in this article are included in the article's Creative Commons licence, unless indicated otherwise in a credit line to the material. If material is not included in the article's Creative Commons licence and your intended use is not permitted by statutory regulation or exceeds the permitted use, you will need to obtain permission directly from the copyright holder. To view a copy of this licence, visit http://creativecommons.org/licenses/by/4.0/. 


\section{References}

Aiken, L. S., \& West, S. G. (1991). Multiple regression: Testing and interpreting interactions. Thousand Oaks: Sage.

Alivernini, F., Cavicchiolo, E., Manganelli, S., Chirico, A., \& Lucidi, F. (2020). Students' psychological well-being and its multilevel relationship with immigrant background, gender, socioeconomic status, achievement, and class size. School Effectiveness and School Improvement, 31(2), 172-191.

Alivernini, F., \& Lucidi, F. (2011). Relationship between social context, self-efficacy, motivation, academic achievement, and intention to drop out of high school: A longitudinal study. The Journal of Educational Research, 104(4), 241-252.

Alivernini, F., \& Manganelli, S. (2016). The Classmates Social Isolation Questionnaire (CSIQ): An initial validation. European Journal of Developmental Psychology, 13, 264-274.

Alivernini, F., Manganelli, S., Cavicchiolo, E., \& Lucidi, F. (2019). Measuring bullying and victimization among immigrant and native primary school students: Evidence from Italy. Journal of Psychoeducational Assessment, 37(2), 226-238.

Alivernini, F., Manganelli, S., \& Lucidi, F. (2018). Personal and classroom achievement goals: Their structures and relationships. Journal of Psychoeducational Assessment, 36(4), 354-365.

Alsaker, F., \& Olweus, D. (1986). Assessment of global negative selfevaluations and perceived stability of self in Norwegian preadolescents and adolescents. The Journal of Early Adolescence, 6(3), 269-278.

Archambault, I., Janosz, M., Dupéré, V., Brault, M. C., \& Andrew, M. M. (2017). Individual, social, and family factors associated with high school dropout among low-SES youth: Differential effects as a function of immigrant status. British Journal of Educational Psychology, 87(3), 456-477.

Bianchi, D., Lonigro, A., Baiocco, R., Baumgartner, E., \& Laghi, F. (2020). Social anxiety and peer communication quality during adolescence: The interaction of social avoidance, empathic concern and perspective taking. Child \& Youth Care Forum, 49(6), 853-876.

Birkeland, M. S., Breivik, K., \& Wold, B. (2014). Peer acceptance protects global self-esteem from negative effects of low closeness to parents during adolescence and early adulthood. Journal of Youth and Adolescence, 43(1), 70-80.

Bizumic, B., Reynolds, K. J., Turner, J. C., Bromhead, D., \& Subasic, E. (2009). The role of the group in individual functioning: School identification and the psychological well-being of staff and students. Applied Psychology-an International Review-Psychologie Appliquee-Revue Internationale, 58(1), 171-192.

Blackhart, G. C., Nelson, B. C., Knowles, M. L., \& Baumeister, R. F. (2009). Rejection elicits emotional reactions but neither causes immediate distress nor lowers self-esteem: A meta-analytic review of 192 studies on social exclusion. Personality and Social Psychology Review, 13(4), 269-309.

Bleidorn, W., Arslan, R. C., Denissen, J. J., Rentfrow, P. J., Gebauer, J. E., Potter, J., \& Gosling, S. D. (2016). Age and gender differences in self-esteem-A cross-cultural window. Journal of Personality and Social Psychology, 111(3), 396-410.

Brown, B. B., \& Larson, J. (2009). Peer relationships in adolescence. In R. M. Lerner \& L. Steinberg (Eds.), Handbook of adolescent psychology. Hoboken: Wiley.

Carsley, D., Heath, N. L., Gomez-Garibello, C., \& Mills, D. J. (2017). The importance of mindfulness in explaining the relationship between adolescents' anxiety and dropout intentions. School Mental Health, 9(1), 78-86.

Cavicchiolo, E., Girelli, L., Lucidi, F., Manganelli, S., \& Alivernini, F. (2019). The Classmates Social Isolation Questionnaire for Adolescents (CSIQ-A): Validation and invariance across immigrant background, gender and socioeconomic level. Journal of Educational, Cultural and Psychological Studies (ECPS Journal), 19, 163-174.

Cornell, D., Gregory, A., Huang, F., \& Fan, X. (2013). Perceived prevalence of teasing and bullying predicts high school dropout rates. Journal of Educational Psychology, 105, 138-149.

Crispin, L. M. (2017). Extracurricular participation, "at-risk" status, and the high school dropout decision. Education Finance and Policy, 12, 166-199.

Davis, L., Ajzen, I., Saunders, J., \& Williams, T. (2002). The decision of African American students to complete high school: An application of the theory of planned behavior. Journal of Educational Psychology, 94(4), 810-819.

Dickhäuser, O., \& Plenter, I. (2005). "Letztes Halbjahr stand ich zwei”. Zur Akkuratheit selbst berichteter Noten ["Last term I had a B". On the accuracy of self-reported school grades]. Zeitschrift für Pädagogische Psychologie, 19(4), 219-224.

Dimitrova, R., Chasiotis, A., \& Van de Vijver, F. (2016). Adjustment outcomes of immigrant children and youth in Europe. European Psychologist, 21(2), 150-162.

Duncan, G. J., \& Murnane, R. J. (2011). Whither opportunity? Rising inequality, schools, and children's life chances. New York, NY: Russel Sage Foundation.

Eicher, V., Staerklé, C., \& Clémence, A. (2014). I want to quit education: A longitudinal study of stress and optimism as predictors of school dropout intention. Journal of Adolescence, 37(7), $1021-1030$.

Foundation for Initiatives and Studies on Multi-Ethnicity, ISMU. (2020). The Twenty-fifth Italian Report on Migrations 2019 (National Report). Retrieved February, 2020, from https://www. ismu.org/the-twenty-fifth-italian-report-on-migrations-2019/.

Glaser, D. J. (2009). Teenage dropouts and drug use: Does the specification of peer group structure matter? Economics of Education Review, 28, 497-504.

Gummadam, P., Pittman, L. D., \& Ioffe, M. (2016). School belonging, ethnic identity, and psychological adjustment among ethnic minority college students. The Journal of Experimental Education, 84(2), 289-306.

Hardre, P. L., \& Reeve, J. (2003). A motivational model of rural students' intentions to persist in, versus drop out of, high school. Journal of Educational Psychology, 95(2), 347-356.

Harris, J. R. (1995). Where is the child's environment? A group socialization theory of development. Psychological Review, 102(3), $458-489$.

Hu, L. T., \& Bentler, P. M. (1999). Cutoff criteria for fit indexes in covariance structure analysis: Conventional criteria versus new alternatives. Structural Equation Modeling: A Multidisciplinary Journal, 6(1), 1-55.

Huang, C. (2010). Mean-level change in self-esteem from childhood through adulthood: Meta-analysis of longitudinal studies. Review of General Psychology, 14(3), 251-260.

Huang, C., \& Dong, N. (2012). Factor structures of the Rosenberg Self-Esteem Scale: A meta-analysis of pattern matrices. European Journal of Psychological Assessment, 28(2), 132-138.

Kaplan, D. (2000). Structural equation modelling. Foundations and extensions. Thousand Oaks: Sage.

Klimidis, S., Stuart, G., Minas, I. H., \& Ata, A. W. (1994). Immigrant status and gender effects on psychopathology and self-concept in adolescents: a test of the migration-morbidity hypothesis. Comprehensive Psychiatry, 35(5), 393-404.

Korhonen, J., Linnanmäki, K., \& Aunio, P. (2014). Learning difficulties, academic well-being and educational dropout: A personcentred approach. Learning and Individual Differences, 31, 1-10.

Leary, M. R. (2005). Sociometer theory and the pursuit of relational value: Getting to the root of self-esteem. European Review of Social Psychology, 16(1), 75-111. 
Lee, J., Chun, J., Kim, J., \& Lee, J. (2020). Cyberbullying victimisation and school dropout intention among South Korean adolescents: The moderating role of peer/teacher support. Asia Pacific Journal of Social Work and Development. https://doi.org/10.1080/02185 385.2020.1774409.

Liebkind, K., Jasinskaja-Lahti, I., \& Solheim, E. (2004). Cultural identity, perceived discrimination, and parental support as determinants of immigrants' school adjustments: Vietnamese youth in Finland. Journal of Adolescent Research, 19(6), 635-656.

Mahoney, J. L. (2014). School extracurricular activity participation and early school dropout: A mixed-method study of the role of peer social networks. Journal of Educational and Developmental Psychology, 4, 143-154.

Martini, A. (2016). La prova nazionale INVALSI e l'esame di conclusione del primo ciclo. INVALSI. Retrieved February, 2020, from https://www.invalsi.it/download2/wp/wp28_Martini.pdf.

Matthews, L. (2017). Applying multigroup analysis in PLS-SEM: A step-by-step process. In H. Latan \& R. Noonan (Eds.), Partial least squares path modeling. Cham: Springer.

Mc Andrew, M., Balde, A., Bakhshaei, M., Tardif-Grenier, K., Audet, G., Armand, F., ... Rousseau, C. (2015). La réussite éducative des élèves issus de l'immigration: dix ans de recherche et d'intervention au Québec [Educational Achievement of Immigrant Students: Ten Years of Research and Intervention in Quebec]. Montréal, QC: Presses de l'Universitée de Montréal.

Milione, A. (2011). Young immigrants at school: Inclusion and location of rights in Italy. Italian Journal of Sociology of Education, 3(2), 173-198.

Ministry of Education, Universities and Research [MIUR]. (2019). Gli alunni con cittadinanza non italiana A.S. 2017/2018 [Students with non-Italian citizenship 2017-2018] Retrieved February, 2020, from https://miur.gov.it/documents/20182/250189/Notiz iario+Stranieri+1718.pdf/78ab53c4-dd30-0c0f-7f40-bf22bbcedf $\mathrm{a} 6$ ? version $=1.2 \& \mathrm{t}=1562937526726$.

Motti-Stefanidi, F., Pavlopoulos, V., Mastrotheodoros, S., \& Asendorpf, J. B. (2020). Longitudinal interplay between peer likeability and youth's adaptation and psychological well-being: A study of immigrant and nonimmigrant adolescents in the school context. International Journal of Behavioral Development. https ://doi.org/10.1177/0165025419894721.

Muthén, L. K., \& Muthén, B. O. (2017). MPlus: statistical analysis with latent variables--User's guide (Version 8). Los Angeles, CA.

Niepel, C., Brunner, M., \& Preckel, F. (2014). Achievement goals, academic self-concept, and school grades in mathematics: Longitudinal reciprocal relations in above average ability secondary school students. Contemporary Educational Psychology, 39(4), 301-313.

Ogle, R. R., Frazier, S. L., Nichols-Lopez, K., \& Cappella, E. (2016). Non-academic self-concept among urban youth: Associations with academic success. School Mental Health, 8(2), 278-291.

Oh, J. A., Jung, Y. T., \& Lee, Y. J. (2018). The aim of this study is to analyze risk factors that affect school dropout of multicultural adolescents. International Journal of Pure and Applied Mathematics, 118(19), 935-949.

Organization for Economic Co-Operation and Development. (2014). PISA 2012 technical report. Programme for International Student Assessment, Organisation for Economic Co-Operation and Development Publishing. Retrieved February, 2020, from https://www. oecd.org/pisa/pisaproducts/PISA-2012-technical-report-final.pdf.

Orth, U., Robins, R. W., Widaman, K. F., \& Conger, R. D. (2014). Is low self-esteem a risk factor for depression? Findings from a longitudinal study of Mexican-origin youth. Developmental Psychology, 50(2), 622-633.

Palladino, B. E., Nappa, M. R., Zambuto, V., \& Menesini, E. (2020). Ethnic bullying victimization in Italy: the role of acculturation orientation for ethnic minority adolescents with differing citizenship statuses. Frontiers in Psychology, 11, 499. https://doi.org/10.3389/ fpsyg.2020.00499.

Pinto, A., Veríssimo, M., Gatinho, A., Santos, A. J., \& Vaughn, B. E. (2015). Direct and indirect relations between parent-child attachments, peer acceptance, and self-esteem for preschool children. Attachment \& Human Development, 17(6), 586-598.

Plenty, S., \& Jonsson, J. O. (2017). Social exclusion among peers: The role of immigrant status and classroom immigrant density. Journal of Youth and Adolescence, 46(6), 1275-1288.

Ponterotto, J. G., \& Ruckdeschel, D. E. (2007). An overview of coefficient alpha and a reliability matrix for estimating adequacy of internal consistency coefficients with psychological research measures. Perceptual and Motor Skills, 105(3), 997-1014.

Portes, A., \& Rumbaut, R. G. (2001). Legacies: The story of the immigrant second generation. Berkeley, CA: University of California Press.

Prezza, M., Trombaccia, F. R., \& Armento, R. (1997). La scala dell'autostima di Rosenberg: traduzione e validazione italiana [Rosenberg's self-esteem scale: Italian translation and validation]. Bollettino di Psicologia Applicata, 223, 35-44.

Renshaw, T. L., \& Bolognino, S. J. (2017). Psychometrics of the psychological wellbeing and distress screener: A brief measure of youth's bidimensional mental health. Assessment for Effective Intervention, 42(3), 160-167.

Ripamonti, E. (2018). Risk factors for dropping out of high school: A review of contemporary, international empirical research. Adolescent Research Review, 3(3), 321-338.

Rhodes, J., Roffman, J., Reddy, R., \& Fredriksen, K. (2004). Changes in self-esteem during the middle school years: A latent growth curve study of individual and contextual influences. Journal of School Psychology, 42(3), 243-261.

Rosenberg, M. (1965). Society and the adolescent self-image. Princeton: Princeton University Press.

Rubin, K. H., Bukowski, W. M., \& Parker, J. G. (2006). Peer interactions, relationships, and groups. Handbook of child psychology (pp. 571-645). Hoboken, NJ: Wiley.

Rumberger, R. W., \& Lim, S. A. (2008). Why students drop out of school: A review of 25 years of research. Santa Barbara, CA: California Dropout Research Project. Retrieved February, 2020, from https://www.issuelab.org/resources/11658/11658.pdf.

Schwartz, S. J., Unger, J. B., Zamboanga, B. L., \& Szapocznik, J. (2010). Rethinking the concept of acculturation: Implications for theory and research. American Psychologist, 65(4), 237-251.

Sinclair, S. J., Blais, M. A., Gansler, D. A., Sandberg, E., Bistis, K., \& LoCicero, A. (2010). Psychometric properties of the Rosenberg Self-Esteem Scale: Overall and across demographic groups living within the United States. Evaluation \& the Health Professions, 33(1), 56-80.

Sowislo, J. F., \& Orth, U. (2013). Does low self-esteem predict depression and anxiety? A meta-analysis of longitudinal studies. Psychological Bulletin, 139(1), 213-240.

Suárez-Orozco, C., Motti-Stefanidi, F., Marks, A., \& Katsiaficas, D. (2018). An integrative risk and resilience model for understanding the adaptation of immigrant-origin children and youth. American Psychologist, 73(6), 781-796.

Tabachnick, B. G., \& Fidell, L. S. (2013). Using multivariate statistics (6th ed.). Boston, MA: Pearson.

Van der Vorst, H., Engels, R. C., Meeus, W., \& Deković, M. (2006). Parental attachment, parental control, and early development of alcohol use: A longitudinal study. Psychology of Addictive Behaviors, 20(2), 107.

Vedder, P., Boekaerts, M., \& Seegers, G. (2005). Perceived social support and well-being in school: The role of students' ethnicity. Journal of Youth and Adolescence, 34, 269-278.

Veselska, Z., Madarasova Geckova, A., Gajdosova, B., Orosova, O., van Dijk, J. P., \& Reijneveld, S. A. (2010). Socio-economic 
differences in self-esteem of adolescents influenced by personality, mental health and social support. European Journal of Public Health, 20(6), 647-652.

Wadsworth, M. E., Raviv, T., Reinhard, C., Wolff, B., Santiago, C. D., \& Einhorn, L. (2008). An indirect effects model of the association between poverty and child functioning: The role of children's poverty-related stress. Journal of Loss and Trauma, 13(2-3), $156-185$.

Weeks, M. R., \& Sullivan, A. L. (2019). Discrimination matters: Relations of perceived discrimination to student mental health. School Mental Health, 11(3), 425-437.

Wells, D., Miller, M., Tobacyk, J., \& Clanton, R. (2002). Using a psychoeducational approach to increase the self-esteem of adolescents at high risk for dropping out. Adolescence, 37(146), $431-435$
Zhou, J., Huebner, E. S., \& Tian, L. (2020). Longitudinal associations and mechanisms between achievement goals and subjective wellbeing in school in Chinese adolescents. School Mental Health, $12,353-365$.

Publisher's Note Springer Nature remains neutral with regard to jurisdictional claims in published maps and institutional affiliations. 